\title{
A REFLEXÃO NA PRÁTICA DOCENTE: ALGUNS LIMITES PARA A SUA EFECTIVAÇÃO. O CASO DA INFORMÁTICA NA EDUCAÇÃO
}

\section{Leonel Jorge Ribeiro Nunes}

Doutorando em Didáctica das Ciências Geológicas

\section{A PERSPECTIVA DO PROFESSOR REFLEXIVO}

A perspectiva do professor reflexivo é uma das mais recentes tendências de pesquisa em educação. Mesmo sem terem originalmente reparado na formação de professores, os estudos de Schon estão na base da formulação da teoria sobre o professor reflexivo. Partindo da constatação de que há uma crise de confiança nos profissionais, Schon, nas suas pesquisas sobre a formação profissional, procura entender como se dá a aquisição dos saberes que os profissionais carregam, em particular os que ele denomina de bons profissionais.

Apoiado nos pressupostos do pensamento de Dewey, em particular a conceptualização de experiência, Schon formula a sua perspectiva em torno de três aspectos: conhecimento prático, reflexão da prática, reflexão sobre a prática e sobre a reflexão sobre a prática.

Para Shon, o professor possui um conhecimento que utiliza para a solução de diferentes questões. É um conhecimento tácito, ou um conhecimento adquirido na prática. Este conhecimento «manifesta-se na espontaneidade» (Alarcão, 1996) e portanto não sistematizado. É um conhecimento que se expressa na execução de uma dada tarefa, sem ter a necessidade de uma reflexão prévia.

$\mathrm{Na}$ medida em que o professor coloca para si as questões do quotidiano como situações problemáticas, está a reflectir, está à procura de uma interpretação para aquilo que é vivenciado. Quando o professor faz esta reflexão ao mesmo tempo em que vivencia uma determinada situação, para Schon, ele faz uma reflexão na acção. Esta etapa permite uma reorientação da acção no exacto momento em que a está a viver. Se esta reflexão se dá após a acção e tem carácter retrospectivo, o professor reflecte sobre a acção. Há então um certo distanciamento, um olhar distinto daquele que vivenciou aquela acção.

Por fim, um outro momento deste processo de reflexão é a reflexão sobre a reflexão na acção. Aí dá-se um processo mais elaborado onde o próprio profissional procura a compreensão da acção, elabora sua interpretação e tem condições de criar outras alternativas para aquela situação.

Schon percebe que o processo de formação, principalmente dado nas universidades, apresenta um esquema que distancia a teoria da prática, pois primeiro é fornecida ao aluno a teoria e só no final do seu curso tem um estágio prático. Deste modo tem relevância um conhecimento aplicado, onde a teoria traz em si mesma as questões que poderiam ser suscitadas pela prática e, ao mesmo tempo, a sua solução. É o 
paradigma da racionalidade técnica, que, segundo Gómez, privilegia o saber académico em detrimento do saber prático.

Desta formulação, surge a proposta de uma outra epistemologia da prática, reconhecendo a riqueza da docência, dada pela prática dos bons profissionais. O foco deslocase da teoria para a valorização do conhecimento que surge a partir da prática e da reflexão sobre a prática, pensando em educação, são os saberes característicos da docência (Pimenta, 1999).

Esta elaboração de Schon dá uma relevância ao papel da reflexão na questão da formação e da prática profissional, pode-se dizer que ela assume posição central na sua proposta de epistemologia.

\section{A REFLEXÃO NA PRÁtICA DOCENTE}

A base desta epistemologia proposta por Schon é a reflexão da prática. O que significa, então, reflectir a prática? Esta proposição pretende superar a «omnisciência» da racionalidade técnica instrumental, onde o conhecimento é algo distinto da prática e tem com ela uma relação linear e definida. No processo de reelaboração do saber proposto por esta epistemologia, a prática é entendida também como fonte de conhecimento e locus de produção de saber. Para tanto, a reflexão apresentase muito além do que um simples meio de efectivação do novo saber.

Para Gómez (1992) «a reflexão implica a imersão consciente do homem no mundo da sua experiência, um mundo carregado de conotação, valores, intercâmbios simbólicos, correspondências afectivas, interesses sociais e cenários políticos». Reflectir, portanto, traz o elemento da inflexão consciente na prática. A reflexão dá-se entre o pensamento e a acção, dentro das próprias relações sociais, interferindo nas práticas a fim de as reconstruir.

Também neste sentido, Matos (1998) reafirma que «a reflexão implica um distanciamento, uma verificação à distância», sendo assim um acto consciente. Este autor procura demonstrar que a reflexão vai muito além da simples tradição cartesiana do "cogito", pois implica a acção deliberada do sujeito, é «inerente à natureza do ser humano». Para ele, a reflexão é uma possibilidade de «diálogo travado entre o ser humano e o seu mundo».

Reflectir a prática apresenta-se, então, com dois aspectos complementares: por um lado indica a necessidade de interferência na prática, da sua modificação por um processo próprio, intrínseco à pessoa. Por outro lado, reflectir a prática é praticar a reflexão, ou seja, dinamizar a vivência através de um processo recriador, adoptando como perspectiva a possibilidade inerente de construção de um novo saber.

A compreensão da reflexão envolta nas tramas do quotidiano dá uma dimensão dinâmica a este processo, pois carrega-o com a complexidade da própria vida quotidiana. A prática não é só o objecto da reflexão, é também objecto de uma ressignificação (Pimenta, 1999). 
Entendida assim, a reflexão submete-se à categoria do tempo. A cada reflexão tem-se uma nova teia de relações sociais e interpessoais, particularizando tal situação e explicitando a sua especificidade. De outro modo, o tempo da reflexão é também um tempo específico e determinado. Aqui, não se pensa no tempo exclusivamente no seu aspecto cronológico. A percepção do tempo caminha além do ritmo das horas, incorporando representações, interpretações, sensações e sentimentos.

Reflectir a prática é, assim, uma dinâmica em que o tempo se mostra como delineador daquela situação específica. Neste sentido é que se podem entender as diversas leituras e mesmo releituras da prática. A reflexão transforma-se num elemento dinamizador da prática, condicionada a um tempo específico.

Para Perrenoud (1998), se a prática reflexiva é adquirida desde a formação inicial torna-se parte da identidade profissional do professor. Deste modo, a reflexão é entendida como característica do fazer profissional. Aproxima-se mesmo da identidade profissional. Daí vem o seu carácter dinamizador, que é apenas possível com uma compreensão não linear e não unívoca do tempo.

\section{A REFLEXÃO, A ROTINA E O HABITUS}

A análise da reflexão na prática docente não isenta a constatação da dificuldade da sua efectivação. No seu trabalho diário o professor utiliza o seu conhecimento na prática, aquilo que tem acumulado de vivências anteriores, de forma por vezes desarticulada e que utiliza nas situações mais correntes e mesmo nas situações excepcionais da sua prática.

Esta colocação apoia-se em Dewey que faz a distinção entre a prática reflexiva e a rotina. Para este autor, a rotina está baseada no impulso, na tradição e na autoridade. É o contrário da prática reflexiva, pois não há questionamento daquilo que é vivido, e sim, uma aceitação acrítica da realidade e das ordens emanadas pelas autoridades.

Diferente é a percepção que Perrenoud (1997) tem ao analisar a prática docente, retomando o conceito de habitus, utilizado por Bourdieu, a fim de caracterizar aquela acção do professor que foi regulada não por um processo iminentemente reflexivo, mas sim resultante do acumular de saberes. Para Bourdieu, o habitus é "esse conjunto de esquemas que permite engendrar uma infinidade de práticas adaptadas a situações sempre renovadas sem nunca se constituir em princípios explícitos» (Perrenoud, 1997).

Na sua prática quotidiana, o professor utiliza este habitus como forma de efectivação do seu fazer docente. Pressionado, por vezes, por situações inusitadas ou mesmo diante da situação mais simples, o professor faz valer os seus esquemas presentes na sua vida profissional, dando um sentido e uma orientação ao que acontece na sua prática.

O sentido que Bourdieu assume para a concepção do habitus é a de uma garantia da conformidade de determinadas práticas e da sua permanência através do tempo, a partir da «interiorização dos 
constrangimentos externos, da incorporação das estruturas sociais». Deste modo, o professor assume todas estas estruturas e utiliza-as como um dos elementos definidores da sua prática.

Para Perrenoud, apoiado em Bourdieu, trata-se portanto não só de reflectir a prática como também transformar o habitus. Não se pode entender o habitus como uma mera aplicação inconsciente de formas de pensar e esquemas interiorizados. Trata-se, sim, da atribuição de sentidos para além do simples entendimento racional. A formação do habitus no professor é o resultado deste processo contraditório que acorre no seu fazer diário, onde entram os elementos da sua formação, do seu viver, das suas expectativas.

Qual seria, então, a relação entre reflexão e o habitus? Numa primeira aproximação, poder-se-ia entender que ocupam lugares distintos e contrários dentro da prática docente, na medida em que a reflexão teria, por essência, a consciencialização do que a prática traz em si, e o habitus estaria apoiado exactamente na não percepção consciente dos actos práticos, porém efectivos. Deste modo, a prática reflexiva teria o «sinal invertido» em relação ao habitus, ou seja, quanto mais se «usasse» a prática reflexiva, menos o professor teria que servir-se do habitus para conduzir o seu fazer quotidiano. Reflectir a prática é também «reflectir o e sobre» o habitus. O habitus é também formado pela reflexão. Por outras palavras, há uma interpenetração destes dois momentos da prática do professor. Por isso, a relação entre o habitus e a reflexão é uma dinâmica que se estabelece no fazer do professor, são pólos distintos e interligados, que ganham uma significação específica dada pelo professor.

Esta relação é, por vezes, contraditória na medida mesmo em que a prática do professor é conflituosa.

\section{A INFORMÁTICA NA EDUCAÇÃO}

A fim de elucidar aquilo que se disse anteriormente, vai-se analisar uma situação concreta que é a introdução da informática na educação em Portugal e a relação com a perspectiva do professor reflexivo. Vai-se examinar como uma determinada vertente de interpretação da presença da informática na educação em Portugal trata a questão da reflexão na prática docente.

O processo de introdução da informática na educação remonta a década de 80 . A perspectiva de informática que mais resultados produziu em Portugal assentou nas pesquisas de Seymour Papert, que criou a linguagem LOGO, baseada nos estudos de Jean Piaget sobre a cognição e as etapas de desenvolvimento infantil.

O objectivo da aplicação desta linguagem era concretizar uma proposta de aprendizagem onde o aluno fosse o sujeito deste processo. Para tanto, havia a necessidade de «formar» os professores para a prática da educação com informática. Valente (1993) aprimora a discussão sobre a formação de professores para trabalhar com informática introduzindo um esquema a partir daquilo que é trabalhado pelo próprio professor. Para ele, o trabalho com computadores deve orientar-se pelo ciclo descrição-execução- 
reflexão-depuração. Este ciclo de actividades pretende possibilitar ao professor um processo de reflexão sobre o que está a ser trabalhado.

Para realizar qualquer actividade com os computadores, o professor deve percorrer este caminho, ou seja, elaborar/descrever o que será feito, por outras palavras, o professor vai criar estratégias junto ao computador para poder obter o resultado pretendido. Esta é a lógica da programação dos computadores. Uma vez feito isto, o professor deve executar tais estratégias e, então, fazer a reflexão sobre o que foi obtido como resultado, comparando com aquilo que era esperado/pretendido. Uma vez identificadas diferenças entre o que foi proposto e o que foi executado, o professor deve depurar o seu trabalho anterior e reelaborá-lo seguindo o ciclo.

A proposta da aplicação deste ciclo tem alcançado diferentes situações no processo de introdução da informática na educação. Conforme observa Almeida (1996), há uma forte identificação entre a proposta de formação do professor reflexivo e o trabalho com o ciclo descrição-execução-reflexão-depuração. Para esta autora, apenas a elaboração e execução das etapas do ciclo poderão dar ao professor aquilo que é proposto pela perspectiva do professor reflexivo, ou seja, ter o domínio da sua prática e a produção consciente do saber utilizando a informática.

Ripper (1996), analisando a formação de professores para o uso das novas tecnologias, alerta para a necessidade de formá-los para uma nova etapa que a humanidade está a viver. Para esta autora, a forma como até agora os professores estão a ser formados corresponde ao modelo da chamada primeira revolução industrial, onde a produção em série é o que importa. Neste sentido, o professor era tido como eficiente na medida em que conseguia transmitir da melhor forma possível os conhecimentos já acumulados pela sociedade. Correspondia plenamente ao modelo da racionalidade técnica e instrumental.

Com as mudanças provocadas pela sociedade da informação, não mais é possível pensar-se em mera reprodução do conhecimento. Com as novas relações de trabalho «é necessário um trabalhador capaz de trabalho cooperativo e de análise e síntese de conhecimento» (Ripper, 1996). Esta passa a ser a exigência colocada para a escola no sentido da formação do trabalhador.

Deste modo, a prática da reflexão tem sido vista por esta perspectiva como a possibilidade de redirecionamento da educação. No caso da informática, segundo Almeida (1996), é através da utilização do ciclo descrição-execução-reflexão-depuração que se pode concretizar esta formação do professor, uma vez que é na prática do uso dos computadores através do ciclo que tal reflexão se dará.

Segundo esta perspectiva, a utilização do ciclo permite ao professor ter o computador como uma ferramenta de «pensar-com» e «pensar-sobre-o-pensar», correspondentes aos momentos de reflexão na acção e reflexão sobre a acção. É a «tomada de consciência» sobre o processo de ensino aprendizagem, requerida pelo próprio processo pedagógico. 
A apresentação desta perspectiva de utilização da informática na educação está basicamente calcada na utilização deste ciclo. O esforço de formação tanto de professores como alunos encontra na formulação do professor reflexivo uma correspondência quase linear.

Ao considerar esta forma de utilização dos computadores, vê-se que não há uma apreciação do que se dá na prática, e sim uma proposta de uma determinada prática que deverá ser analisada nas suas diferentes etapas. Ou seja, não se parte dos saberes que se estabelecem na prática docente (tal como entendido por Perrenoud (1998) e Pimenta (1999)), mas sim, uma proposição em torno do uso de computadores. Pode-se argumentar, contrariamente a isto, que dadas as condições actuais não existe efectivamente uma prática de professores com computadores, a ponto de poder ser reflectida. Entretanto, esta é uma visão restricta do que é o reflectir a prática, não incorporando os modos de fazer e de representar a prática docente.

O entendimento do uso dos computadores em educação considerando-se a contradição dinamizadora que se estabelece entre a reflexão e o habitus deve incorporar a prática actual e os modos de representar dos professores sobre o uso de tecnologias em educação. No meu modo de entender, a utilização do ciclo descrição-execução-reflexão-depuração é um dos momentos desta prática reflexiva e não o seu eixo orientador exclusivo, pois assim pode ser limitante do próprio entendimento da prática docente.

\section{CONCLUSÃO}

Apesar de haver diferenças significativas entre as redes de ensino público e a rede privada, pode-se considerar um ambiente comum ao menos nos aspectos aqui reflectidos.

O primeiro dado que se apresenta é a questão de tempo cronológico. A carga de trabalho a que está submetido o professor transforma-se em factor de inviabilização de qualquer outra actividade além da mera docência, ou seja, do tempo de sala de aula. Este facto acarreta uma sobrecarga que não permite a introdução de um outro tempo destinado à reflexão, uma vez que esta necessita desta condição para a sua sistematização.

Outro limite institucional é a definição das políticas de ensino e de capacitação profissional. São poucas as experiências em que o professorado participa activamente na definição de tais políticas, imprimindo aí os seus desejos e opções. Em geral, tais definições ocorrem fora do âmbito da sala de aula e a prática do professor é vista exclusivamente pelo ângulo dos especialistas e administradores. Tal facto obriga os professores a exercerem uma prática que teve a sua definição para além da sua experiência. Este elemento faz com que a prática do professor seja marcada pela instituição em que trabalha, sem ter tido um espaço efectivo de participação.

Um outro limite institucional é que a actividade do professor caracteriza-se pela individualidade. Por outras palavras, não existe uma opção/condição de se trabalhar em termos colectivos ou de grupos. São pequenos os momentos para a elaboração conjunta da sua prática, e quando isto ocorre dá-se, em geral, 
em função de uma avaliação e programação de planeamento externo. Segundo Zeichner, a reflexão, tal como é pautada pela perspectiva do professor reflexivo, é uma actividade colectiva, mesmo que apresente momentos individuais. Ou seja, reflectir é também incorporar o dado dos outros, aquilo que está formulado por alguém que não a própria pessoa. Deste modo, sem haver a possibilidade concreta de trabalho colectivo, a reflexão também fica afectada.

Para além dos limites institucionais, os limites epistemológicos têm um carácter específico e que, em geral, não são compreendidos pelos professores. Falar aqui em limites epistemológicos é considerar as características intrínsecas deste processo de reflexão enquanto possibilidade de produção do conhecimento. Neste sentido, a tensão que se opera entre o habitus e a reflexão surge na prática quotidiana do professor como um limite, dadas as suas condições objectivas de trabalho. Assim, a pergunta, para o professor, está em saber qual dos dois deve prevalecer em tal situação. Quando ocorre algo inesperado na sua sala de aula, deve agir a partir de qual destes dois pólos da tensão?

Uma vez que estes pólos -habitus e reflexão-, se complementam enquanto contradição dinamizadora, não se prevê que um deles vá sobrepor-se ao outro ou até mesmo "criar» uma nova síntese. Deste modo, a prática do professor é formada tanto pelo habitus como pela reflexão. Se ambos dependem de uma rede complexa de factores, dentre elas a história pessoal e profissional de cada um, o seu estatuto epistemológico também.

Um outro dado limitante é a presença dos valores dentro da reflexão. Segundo Zeichner, este é um dos elementos desta prática reflexiva. Aceitar a presença dos valores no fazer do professor é ampliar a compreensão, é ter uma visão de carácter mais holístico.

Não basta entender que a maior perspectiva está no horizonte de uma sociedade mais justa e democrática, como pontua Zeichner, se esta perspectiva também não estiver presente nos valores individuais próprios de cada um.

Outro dado limitador de carácter epistemológico está na compreensão que a reflexão é algo inerente ao ser humano. Matos (1998) enfatiza muito este dado, levando-nos a supor que para ele há uma substituição do «cogito» cartesiano pela reflexão enquanto especificidade da raça humana. Ou seja, não se estaria mais no plano da racionalidade instrumental, mas numa racionalidade humanística, permeada pelas relações sociais.

O entendimento da reflexão como especificidade do ser humano apresenta-se como limitador na medida em que não revela o seu modus operandi, ou seja, não traduz aquilo que acontece em termos da sua presença no quotidiano do professor. A reflexão não é uma característica escondida que irá «despertar do seu sono" a partir de algum facto específico. É uma decisão que o professor toma em termos de um entendimento diferenciado de sua própria prática.

Por fim, deve-se acrescentar que a reflexão ocorre diante das diferentes tensões vivenciadas pelos professores. Como diz Nacarato (1998), o professor vive de modo contraditorio estas tensões. Não dá para 
supor que possa «escolher» qual tensão viver e enfrentar. Deste modo, a reflexão é uma exigência para o fazer docente, muito mais do que uma simples característica, entendida porém a partir das suas contradições próprias. Saber o que vem primeiro -o habitus ou a reflexão- não é uma questão importante, pois a prática docente enquanto eixo dinamizador é alimentada por esta tensão.

\section{REFERÊNCIAS BIBLIOGRÁFICAS}

ALARCÃO, I. (1996): «Reflexão crítica sobre o pensamento de D. Schön e os programas de formação de professores», in: Revista da Faculdade de Educação, n.․ 22, Jul/Dez, São Paulo.

ALMEIDA, M. E. (1996): «Informática e Educação -diretrizes para uma formação reflexiva de professores». Dissertação de Mestrado apresentada no Departamento de Supervisão e Currículo da PUC, São Paulo.

BARROS, V. B. (1996): Informática em Psicopedagogia. São Paulo, SENAC.

GERALDI, C. (1998): Cartografias do trabalho docente. Campinas, Mercado de Letras: Associação Brasileira de Leituras.

GÓMEZ, A. P. (1992): “O pensamento prático do professor -A formação do professor como profissional reflexivo», in: NÓVOA, A.: Profissão professor, $2^{\underline{a}}$ ed. Porto, Porto Editora.

MATOS, J. C. (1998): «Professor reflexivo? Apontamentos para o debate», in: GERALDI, C.: Cartografias do trabalho docente. Campina, Mercado de Letras: Associação Brasileira de Leituras.

NACARATO, A. M. (1998): «O quotidiano do trabalho docente: palco, bastidores e trabalho invisível: abrindo as cortinas», in GERALDI, C. (1998): Cartografias do trabalho docente. Campinas, Mercado de Letras: Associação Brasileira de Leituras.

NÓVOA, A. (1992): Profissão professor, $2^{\mathrm{a}}$ ed. Porto, Porto Editora.

PERRENOUD, P. (1992): Práticas pedagógicas, profissão docente e formação. Lisboa, Dom Quixote.

PERRENOUD, P. (1999): Saber reflectir sobre a prática, objectivo central da formação de professores? Lisboa, Dom Quixote.

PIMENTA, S. G. (1999): Saberes pedagógicos e actividade docente. São Paulo, Cortez.

RIPPER, A. V. (1996): “O preparo do professor para as novas tecnologias», en: BARROS, V. B.: Informática em psicopedagogia. São Paulo, SENAC.

SCHÖN, D. (1998): «Formar professores como profissionais reflexivos», en: NÓVOA, A.: Os professores e sua formação. Lisboa, Dom Quixote.

VALENTE, J. A. (1993): Computadores e conhecimento: repensando a educação. Campinas,UNICAMP.

ZEICHNER, K. (1998): «Para além da divisão entre professor-pesquisador e pesquisador acadêmico", en: GERALDI, C.: Cartografias do trabalho docente. Campinas, Mercado de Letras: Associação Brasileira de Leituras. 


\title{
Contactar
}

Revista lberoamericana de Educación

\author{
Principal OEI
}

